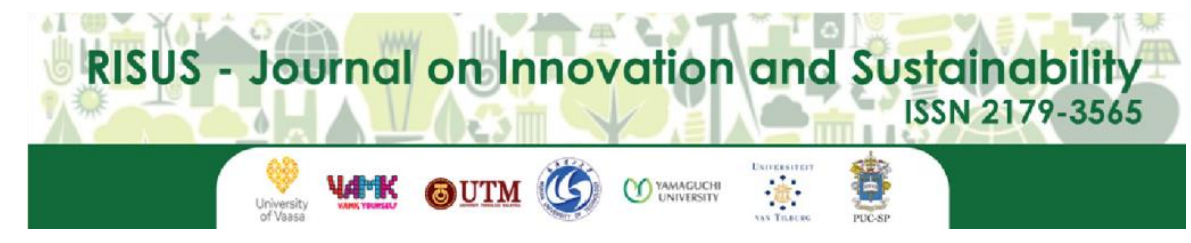

RISUS - Journal on Innovation and Sustainability volume 12, número $1-2021$

ISSN: $2179-3565$

Editor Científico: Arnoldo José de Hoyos Guevara Editor Assistente: Rosa Rizzi

Avaliação: Melhores práticas editoriais da ANPAD

\section{NATURAL SUSCEPTIBILITY TO EROSION IN THE PASTURE AREAS OF THE RIBEIRÃO SANTA CRUZ HYDROGRAPHIC SUB-BASIN, IN THE MUNICIPALITY OF MUNIZ FREIRE (ES)}

Susceptibilidade natural à erosão nas áreas de pastagem da sub-bacia hidrográfica do Ribeirão Santa Cruz, no município de Muniz Freire (ES)
Caio Henrique Ungarato Fiorese Universidade Federal do Espírito Santo E-mail: caiofiorese@ hotmail.com

\begin{abstract}
Livestock, although it has significant economic relevance, is the cause of several problems related to erosion. This fact becomes even more worrying in the context of a hydrographic basin. Thus, the objective of this work was to assess the natural vulnerability to erosion in the pasture areas of the hydrographic sub-basin of the Santa Cruz stream (HBSCS), in order to support improvements related to soil conservation associated with local economic productivity. The procedures took place with the aid of the ArcGIS® geographic information system. The cartographic databases were the websites of GEOBASES, the National Water Agency and the Jones dos Santos Neves Institute. Initially, HBSCS was delimited to later acquire features (vector files) related to the location of pastures covered by HBSCS. The Universal Soil Loss Equation was used to estimate potential erosion. For this, the following data were obtained: erosivity, erodibility, ramp length and slope. Erosion was mapped, quantified and classified. The natural intensity of erosion ranges from 0 ton/ha.year to 6814 ton/ha.year, with an arithmetic mean of 569.740 ton/ha.year and standard deviation equal to 345.013 ton/ha.year. The class with the highest intensity is "moderate to strong". However, when combined, the "moderate to strong" and "strong" classes comprise $65.666 \%$. The lower intensity classes, "weak" and "moderate", together, represent only $33.652 \%$. The values can be attributed, mainly, to the ignorance on the part of the rural producers about the most favorable places for the installation of pastures. Therefore, it is extremely necessary to adopt measures favorable to soil conservation, such as the correct management of livestock, especially in areas with a greater erosive tendency. It is expected that studies with a similar theme will continue, considering, for example, the influence of management on HBSCS erosion.
\end{abstract}

Keywords: Geoprocessing; Natural resource management; Soil loss; Livestock; Rural planning. 


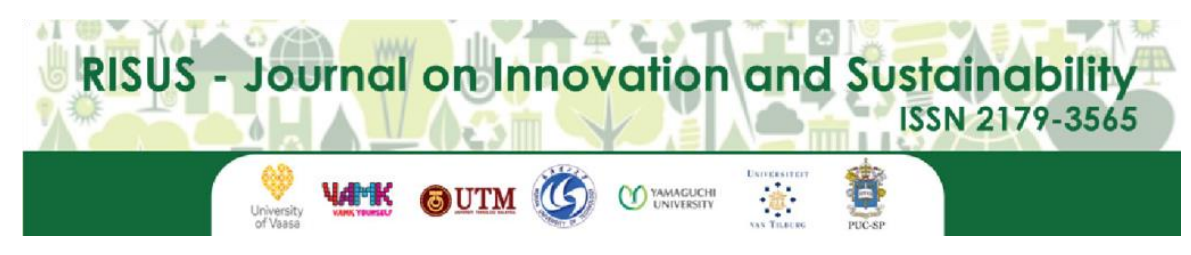

RISUS - Journal on Innovation and Sustainability volume 12, número $1-2021$ ISSN: $2179-3565$

Editor Científico: Arnoldo José de Hoyos Guevara Editor Assistente: Rosa Rizzi

Avaliação: Melhores práticas editoriais da ANPAD

\title{
SUSCEPTIBILIDADE NATURAL À EROSÃO NAS ÁREAS DE PASTAGEM DA SUB- BACIA HIDROGRÁFICA DO RIBEIRÃO SANTA CRUZ, NO MUNICÍPIO DE MUNIZ FREIRE (ES)
}

Natural susceptibility to erosion in the pasture areas of the Ribeirão Santa Cruz hydrographic sub-basin, in the municipality of Muniz Freire (ES)

\author{
Caio Henrique Ungarato Fiorese \\ Universidade Federal do Espírito Santo \\ E-mail: caiofiorese@ hotmail.com
}

\section{RESUMO}

A pecuária, embora possua significativa relevância econômica, é causadora de diversos problemas relacionados à erosão. Tal fato se torna ainda mais preocupante em contexto de bacia hidrográfica. Assim, o objetivo deste trabalho foi avaliar a vulnerabilidade natural à erosão nas áreas de pastagem da sub-bacia hidrográfica do ribeirão Santa Cruz (BHRSC), com a finalidade de apoiar melhorias referentes à conservação dos solos associada com a produtividade econômica local. Os procedimentos ocorreram com auxílio do sistema de informações geográficas ArcGIS ${ }^{\circledR}$. As bases de dados cartográficos foram os sítios eletrônicos do GEOBASES, da Agência Nacional de Águas e do Instituto Jones dos Santos Neves. Inicialmente, foi delimitada a BHRSC para, posteriormente, serem adquiridas feições (arquivos vetoriais) relacionadas à localização das pastagens abrangidas pela BHRSC. A Equação Universal de Perda dos Solos foi considerada para a estimativa da erosão potencial. Para isso, foram obtidos os seguintes dados: erosividade, erodibilidade, comprimento de rampa e declividade. A erosão foi mapeada, quantificada e classificada. A intensidade natural à erosão varia de 0 ton/ha.ano a 6814 ton/ha.ano, com média aritmética de 569,740 ton/ha.ano e desvio padrão igual a 345,013 ton/ha.ano. A classe de maior intensidade é a "moderada a forte". Todavia, quando somadas, as classes "moderada a forte" e "forte" abrangem 65,666\%. Já as classes de menor intensidade, a "fraca" e "moderada", juntas, representam apenas 33,652\%. Os valores podem ser atribuídos, principalmente, ao desconhecimento por parte dos produtores rurais acerca dos locais mais propícios à instalação das pastagens. Portanto, é de extrema necessidade a adoção de medidas favoráveis à conservação dos solos, como o manejo correto da pecuária, principalmente nas áreas com maior tendência erosiva. Espera-se que haja a continuidade de estudos com temática semelhante considerando, por exemplo, a influência do manejo na erosão da BHRSC.

Palavras-chave: Geoprocessamento; Gestão dos recursos naturais; Perda de solo Pecuária; Planejamento rural. 


\section{INTRODUÇÃO}

A pecuária é de suma importância para o país, principalmente por sua participação na economia do Brasil. Todavia, há muitos aspectos negativos gerados por esta atividade, como a degradação e a poluição dos solos e da água. Assim, essa atividade pode ser repensada de forma a conciliar o meio ambiente com o desenvolvimento econômico (Wust, Tagliani \& Concato, 2015).

Na região Sul do estado do Espírito Santo, a pecuária é um setor muito forte na economia. Porém, a mesma encontra muitas limitações para a sua prática correta, como é o caso do relevo que, por sua vez, apresenta várias irregularidades nessa região capixaba. Outros desafios estão associados à erodibilidade e erosividade, pois podem interferir na produtividade econômica e na sustentabilidade da pecuária local. Dessa forma, as características naturais, principalmente quando analisadas em nível de bacia hidrográfica, são um grande desafio para o desenvolvimento da pecuária. Por exemplo, quando da ocupação em áreas naturalmente mais propensas à erosão, a pastagem, associada a um manejo incorreto, pode acarretar problemas ambientais graves.

Nesse sentido, a análise de vulnerabilidade ambiental à erosão hídrica se torna importante, pois fornece informações sobre a maior ou menor susceptibilidade de um ambiente ser degradado, além de fornecer ferramentas para a adequada tomada de decisão sobre os adequados planejamento, uso e ocupação do solo (Cuiabano et al., 2017). Em nível de bacia hidrográfica, sobretudo nas áreas destinadas à agropecuária, o conhecimento acerca dos condicionantes e processos erosivos constitui importante instrumento de gestão ambiental (Morais \& Sales, 2017).

Este trabalho foi elaborado através da problemática relacionada em como está sendo planejada e ocupada a pecuária na sub-bacia hidrográfica do ribeirão Santa Cruz (BHRSC), bem como em saber a potencialidade natural das pastagens locais à erosão. A BHRSC é um recurso natural de extrema relevância para o abastecimento hídrico e econômico em diferentes localidades à montante e jusante de sua foz. Para possivelmente responder ao referido problema, é relevante destacar que, na região estudada, muitas áreas de pastagem apresentam alto nível de degradação, o que, por vezes, está associado à má ocupação dessa atividade em áreas potencialmente naturais.

Assim, o objetivo deste trabalho foi verificar as perdas naturais de solo nas áreas de pastagem da BHRSC, a fim de subsidiar melhorias referentes à conservação dos solos associada com a produtividade econômica local. Foi escolhida essa sub-bacia hidrográfica em virtude da carência de estudos disponíveis na literatura com abordagem na área estudada e com a temática voltada à erosão hídrica dos solos.

\section{REFERENCIAL TEÓRICO}

O agronegócio possui papel relevante na economia brasileira. No entanto, seu desenvolvimento é acompanhado por crescentes preocupações com os impactos ambientais negativos provocados pela agricultura e pecuária nos recursos naturais, que podem repercutir na biodiversidade, na disponibilidade hídrica, na qualidade do ar e do solo e na saúde dos seres humanos (Gomes, 2019). A pecuária tem sido apontada como uma das atividades que mais prejudicam o meio ambiente. As externalidades negativas causadas pela pecuária estão correlacionadas com o principal meio de produção adotado no Brasil, o sistema extensivo, além do emprego de outras técnicas tradicionais de manejo. Este sistema é caracterizado pelo baixo investimento em formação (principalmente quando a terra adquirida já contém algum tipo de pastagem) e manutenção de pastagem (De Zen et al, 2008).

Um dos fatores de desgaste que mais seriamente tem contribuído para a degradação do solo é a erosão. Naturalmente, o solo sempre está sendo erodido em um processo contínuo que pode demorar, em alguns casos, muito tempo para modificar significativamente a paisagem ou interferir no equilíbrio do meio ambiente (Oliveira, Santos \& Araujo, 2017). A erosão hídrica é um processo de degradação do solo que pode ser acarretado tanto por fatores naturais quanto por interferência antrópica. Esta, na maioria das vezes, resulta num processo de erosão acelerada e que pode ser agravada pelas características naturais do meio. Esse desgaste do solo deve ser melhor compreendido quando se objetiva a manutenção ou o aumento da produtividade agrícola e a conservação ambiental, favorecendo a sustentabilidade de agroecossistemas (Panachuki, 2003). A erosão hídrica é tida como 
um dos mais importantes problemas ambientais da atualidade, pois atinge indiscriminadamente regiões agrícolas, centros urbanos e áreas naturais (Morais \& Sales, 2017).

A Política Nacional de Recursos Hídricos, instituída pela Lei $n^{\circ}$ 9.433, de 8 de janeiro de 1997, incorpora princípios e normas para a gestão de recursos hídricos adotando a definição de bacias hidrográficas como unidade de estudo e gestão (Teodoro et al., 2007). As bacias hidrográficas são tidas em nível de planejamento territorial como a unidade básica de análise para o desenvolvimento de ações e medidas estruturais e não estruturais com a perspectiva de integração entre a gestão dos recursos hídricos e a gestão ambiental (Carvalho, 2020). A bacia como unidade territorial de planejamento e gerenciamento propõe uma visão abrangente, pois inclui, em seu plano, as políticas publicas, tecnológicas e de educação, a fim de promover a solução de problemas, a otimização de recursos e a garantia dos usos múltiplos dos recursos naturais. Tais recursos contam com a participação de usuários, autoridades, cientistas, poder público e organizações públicas e privadas com interesse pelo tema (Lima et al., 2016).

O Potencial Natural de Erosão (PNE) estima as perdas de solos em áreas com ausência de vegetação e intervenção antrópica, considerando os aspectos físicos e naturais do meio (Prestes \& Corrêa, 2019). A chamada Equação Universal de Perda de Solos (EUPS), criada por Wischmeier e Smith (1962), é um modelo que utiliza dados pluviométricos, tipos de solos, declividade do terreno e uso do solo para estimar a quantidade de solo perdida em uma determinada área (Moura et al., 2017). O modelo da EUPS tem como objetivo fazer estimativa da erosão do solo a médio e longo prazos, podendo dar subsídios gerais ao planejamento de práticas conservacionistas visando minimizar a perda de solos em níveis aceitáveis (Corrêa \& Pinto, 2012). A EUPS é uma referência em estudos de erosão e perdas de solo e foi o modelo utilizado por considerar os principais fatores naturais e antrópico influentes na erosão. Além disso, possui uma grande aceitação que pode ser percebida pelo grande número de trabalhos desenvolvidos e disponíveis na literatura (Lanza, 2011).

O uso de Sistemas de Informação Geográfica (SIG’s) na determinação de áreas com elevado potencial a erosão dos solos usando a equação do potencial natural de erosão (PNE) baseada na EUPS ajuda a criar um modelo de previsão das perdas de solo, possibilitando a identificação de áreas de risco potencial (Cumbane, Madeira \& Abrantes, 2015). O uso de geotecnologias é um instrumento de grande potencial para o estabelecimento de planos integrados de conservação do solo e da água. A utilização de um SIG destaca-se como um ótimo recurso para mapear e obter respostas às várias questões sobre levantamento de dados do meio físico e planejamento ambiental, principalmente ao descrever os mecanismos das mudanças no meio ambiente, além de auxiliar no planejamento e manejo dos recursos naturais existentes (Magalhães Filho, Ayres \& Sobrinho, 2014).

\section{METODOLOGIA}

A BHRSC fica localizada na área rural da porção sudoeste do município de Muniz Freire, na mesorregião Sul do Estado do Espírito Santo. Com uma área de 75,08 km², possui a pecuária (com percentual de ocupação igual a 51,108\%) como a principal atividade econômica. O clima da região, segundo a classificação de Koppen, é classificado como Cwa, ou seja, clima subtropical de inverno seco, com temperaturas inferiores a $18{ }^{\circ} \mathrm{C}$, e verão quente, com temperaturas superiores a $22{ }^{\circ} \mathrm{C}$ (Embrapa, 2020). As Figuras 1 e 2 mostram, respectivamente, a localização da BHRSC e o mapa de zonas naturais pertencentes à BHRSC. E a Figura 3 evidencia a distribuição espacial das áreas de pastagem abrangidas por essa mesma sub-bacia. 
Figura 1 - Localização da BHRSC

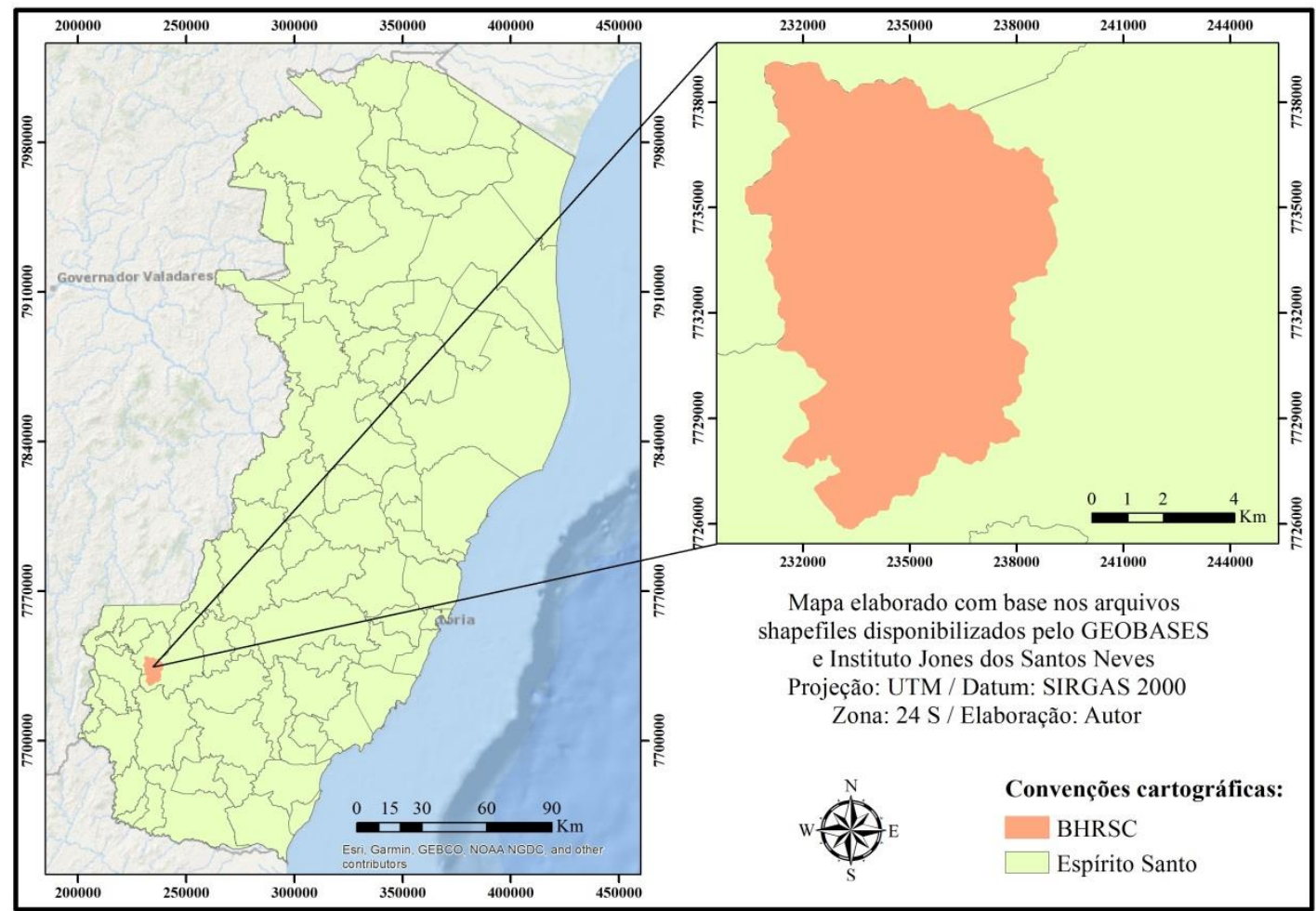

Fonte: Adaptado de GEOBASES (2020) e Instituto Jones dos Santos Neves (2020)

Figura 2 - Mapa de zonas naturais da BHRSC

223000
Mapa - distribuição das zonas
naturais da sub-bacia hidrográfica
do ribeirão Santa Cruz
Projeção: Universal Transversa
de Mercator (UTM)
Datum: SIRGAS 2000
Zona: 24 $\mathbf{S}$
Elaboração: Autor

Fonte: Adaptado de GEOBASES (2020) 
Figura 3 - Localização das áreas de pastagem da BHRSC.

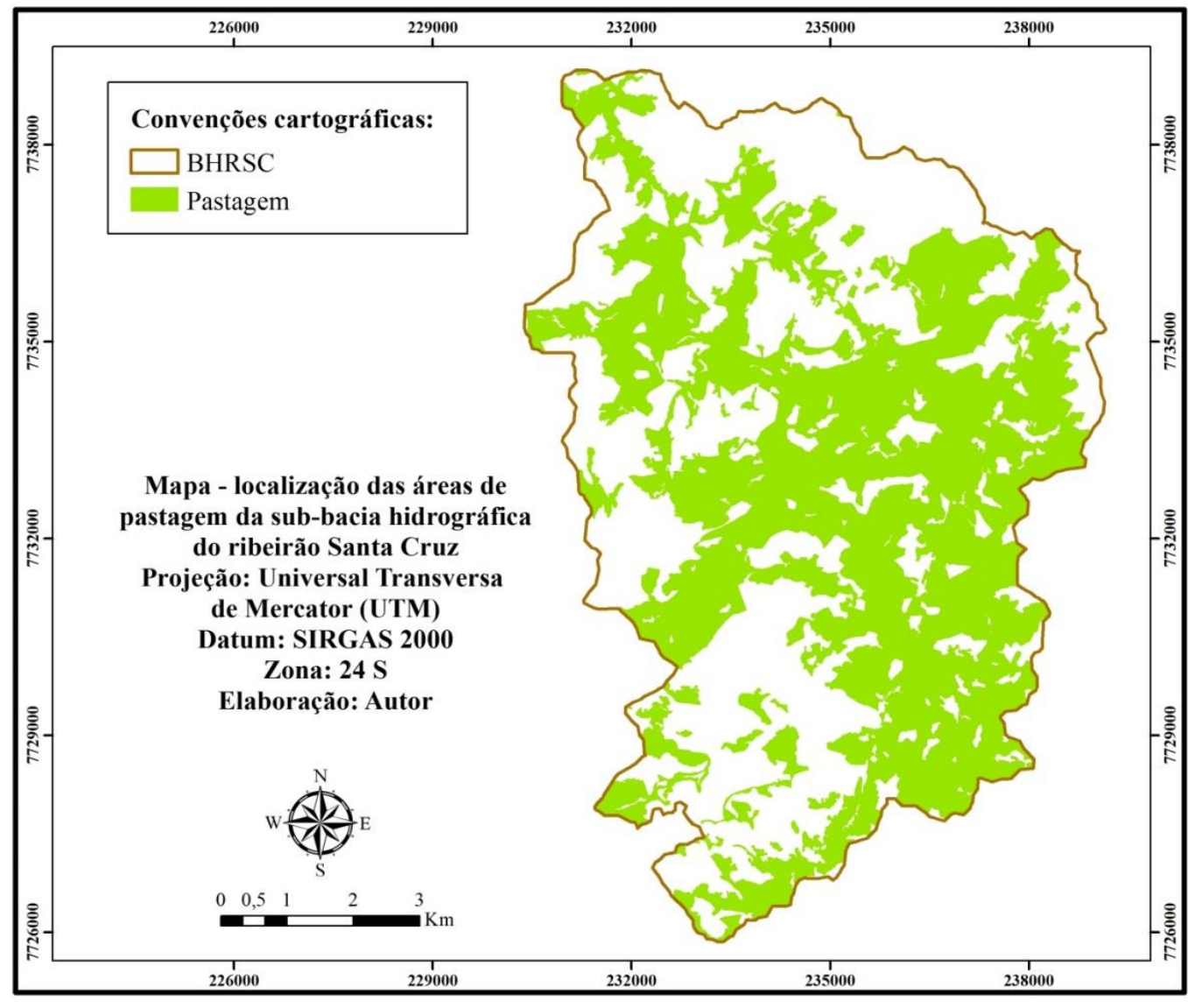

Fonte: Adaptado de GEOBASES

Os procedimentos ocorreram com auxílio de SIG's, no programa computacional ArcGIS®, tendo como bases cartográficas digitais os sítios eletrônicos do Sistema Integrado de Bases Geoespaciais do Estado do Espírito Santo (Geobases, 2020), da Agência Nacional de Águas (Agência Nacional de Águas, 2020) e do Instituto Jones dos Santos Neves (Instituto Jones dos Santos Neves, 2020). Inicialmente, a região de interesse foi identificada a partir de feições ou arquivos vetoriais de municípios do Estado do Espírito Santo adquiridas junto ao portal eletrônico do Instituto Jones dos Santos Neves (IJSN, 2020).

A BHRSC foi delimitada a partir dos seguintes procedimentos (Santos, Louzada \& Eugênio, 2010): aquisição de curvas de nível da região junto ao GEOBASES e seu posterior recorte para a região considerada; geração do Modelo Digital de Elevação (MDE); correção do MDE (para preencher possíveis depressões que possam interferir no escoamento superficial hídrico); delimitação dos fluxos de direção (flow direction) e de acumulação (flow accumulation) da drenagem; identificação do exutório (ponto de deságua) da BHRSC; demarcação do exutório através de um ponto e; delimitação da sub-bacia de interesse.

A identificação e demarcação do exutório da BHRSC ocorreu a partir do auxílio de feições de cursos d'água da região junto ao sítio eletrônico da Agência Nacional de Águas, que carregou as informações dos fluxos hídricos e seus respectivos nomes. A Figura 4 apresenta um fluxograma dos procedimentos percorridos para a delimitação da BHRSC. 
Figura 4 - Fluxograma de delimitação da BHRSC

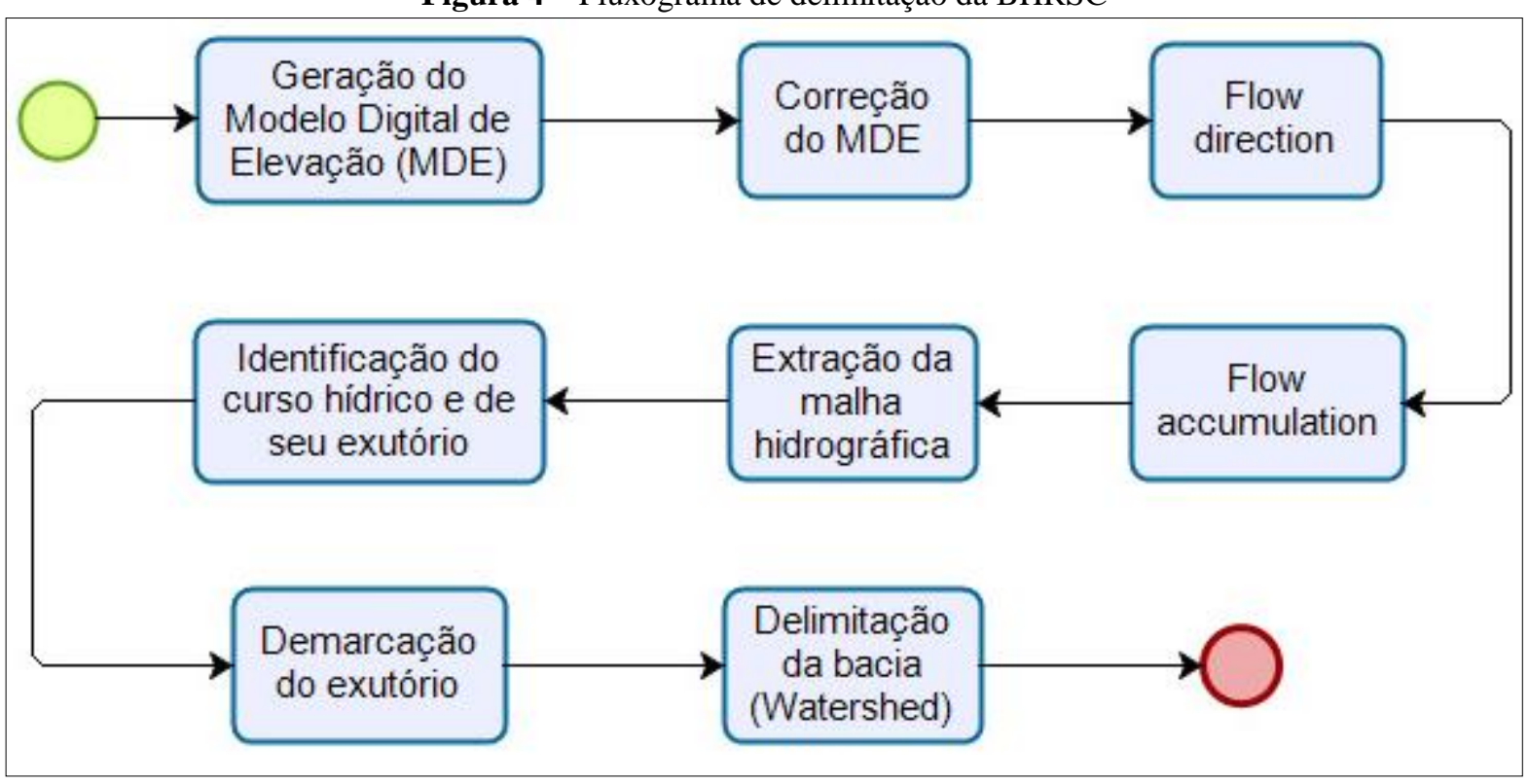

Fonte: Adaptado de Santos, Louzada e Eugênio (2010)

Após a delimitação, foi possível dar prosseguimento aos demais procedimentos de avaliação da perda de solos, desta vez para a região de interesse. As áreas de pastagem da BHRSC foram identificadas por meio da aquisição de feições (arquivos vetoriais) referentes à localização das pastagens. Estas feições foram adquiridas no portal eletrônico do GEOBASES (Geobases, 2020) referentes ao mapeamento plotado nos anos de 2012 a 2015 , em escala igual ou melhor a 1:25000, de acordo com o próprio GEOBASES. Para estimar a perda de solos atual e potencial, foi considerada a EUPS, dada pela equação (1) (Wischmeier \& Smith, 1962):

$$
\mathrm{A}=\mathrm{R} \times \mathrm{K} \times \mathrm{L} \times \mathrm{S} \times \mathrm{C} \times \mathrm{P}
$$

Em que: $\mathrm{A}=$ perda de solo $\left(\mathrm{t} \mathrm{ha}^{-1}\right.$ ano $\left.^{-1}\right) ; \mathrm{R}=$ erosividade da chuva $\left(\mathrm{MJ} \mathrm{ha}^{-1} \mathrm{~mm} \mathrm{~h}^{-1}\right.$ ano $\left.^{-1}\right) ; \mathrm{K}=$ erodibilidade do solo $\left[\mathrm{t} \mathrm{ha}^{-1}\left(\mathrm{MJ} \mathrm{ha}^{-1} \mathrm{~mm} \mathrm{~h}^{-1}\right)^{-1}\right] ; \mathrm{L}=$ comprimento do declive (adimensional); $\mathrm{S}=$ grau de declive (adimensional); $\mathrm{C}=$ uso e manejo do solo (adimensional); $\mathrm{P}=$ práticas conservacionistas (adimensional). $\mathrm{A}$ erosão atual indica as perdas de solo por erosão hídrica considerando a erosão potencial ou potencial natural de erosão e as condições atuais de uso do solo e práticas culturais, ou seja, os valores de C e P (Durães \& Mello, 2016). Portanto, a EUPS, considerando todos os seus parâmetros, indica a erosão atual, estando inerente à ocupação antrópica associada às características naturais da área estudada. Já a erosão potencial, causada apenas pelas propriedades físicas da região estudada, inclui apenas os parâmetros $\mathrm{R}, \mathrm{K}, \mathrm{L}$ e S.

A capacidade da chuva de causar erosão em uma área sem proteção em uma dada localidade é expressa pelo fator numérico R (Wischmeier \& Smith, 1962), que deve ser calculado a partir de índices mensais de erosão, obtidos pela equação (2), desenvolvida por Lombardi Neto e Moldenhauer (1992):

$$
\mathrm{EI} \mathrm{i}=67,355 \times\left(\frac{\mathrm{ri}^{2}}{\mathrm{Pi}}\right)^{0,85}
$$

Em que: EI i = média mensal do índice de erosão $\left(\mathrm{MJ} \mathrm{ha}^{-1} \mathrm{~mm}^{-1}\right)$; ri = precipitação pluvial média mensal, em $\mathrm{mm} ; \mathrm{Pi}=$ precipitação pluvial média anual, em mm. O fator $\mathrm{R}$ corresponde ao somatório dos índices mensais de erosão (Bertoni \& Lombardi Neto, 1999). Os dados de precipitação foram adquiridos junto ao portal eletrônico Hidroweb, da Agência Nacional de Águas (Agência Nacional de Águas, 2020), referentes a uma estação pluviométrica localizada no município de Muniz Freire (ES), localizada nas coordenadas geográficas $\mathrm{S} 20^{\circ} 31^{\prime}$ 42"/ W 41 30' 41" e com uma série histórica pluviométrica de 43 anos. A partir da série histórica adquirida, foram estimados os dados de precipitação pluviométrica média anual e mensal. 
Através do MDE da área estudada, foi gerado o mapa de declividade, em graus, por meio da função "slope" no ArcGIS, para determinar os fatores L e S da EUPS. Na prática, esses dois fatores são considerados conjuntamente, por meio de um termo denominado fator topográfico ou LS, que é obtido a partir da agregação do comprimento das encostas (vertentes) com o gradiente de declividade (grau de inclinação), por meio de modelos matemáticos (Galdino, 2012). Os fatores comprimento de rampa e declividade, embora tenham sido pesquisados separadamente, é mais conveniente considerá-los conjuntamente como um fator LS (Bueno, Arraes \& Miqueloni, 2011).

O método de Bertoni e Lombardi Neto (1990) foi considerado para obter os dados do fator LS. O comprimento de rampa (L) foi estimado a partir da equação (3) (Bertoni \& Lombardi Neto, 1990):

$$
\mathrm{L}=\sqrt{\mathrm{P}^{2}+\left(\frac{\mathrm{D}}{100} \times \mathrm{P}\right)^{2}}
$$

Em que: $\mathrm{L}=$ comprimento de rampa (adimensional); $\mathrm{P}=$ tamanho do pixel considerado $(15 \mathrm{~m}) \mathrm{e} ; \mathrm{D}=$ declividade (em porcentagem). A declividade foi extraída a partir do Modelo Digital de Elevação (MDE) da área gerado pelo método da rede triangulada irregular (TIN) a partir de feições (arquivos vetoriais) de curvas de nível da área estudada com equidistância de $5 \mathrm{~m}$. Tais feições foram cedidas pelo GEOBASES (Geobases, 2020).

Em seguida, foi obtido o fator LS a partir da equação (4), também proposta por Bertoni e Lombardi Neto (1990):

$$
\mathrm{LS}=0,00984 \times \mathrm{L}^{0,63} \times \mathrm{D}^{1,18}
$$

Em que: $\mathrm{LS}=$ fator topográfico (adimensional); $\mathrm{L}=$ comprimento de rampa (adimensional) $\mathrm{e} ; \mathrm{D}=$ declividade (em porcentagem). A inserção das equações ocorreu através da ferramenta "álgebra de mapas", no ArcGIS®.

Alguns solos apresentam maior propensão à erosão do que outros, mesmo quando a cobertura vegetal, a precipitação, o declive e as práticas de controle de erosão são as mesmas. Essa diferença é chamada de erodibilidade do solo (fator K), e ocorre devida às propriedades inerentes ao solo (Bertoni \& Lombardi Neto, 1999). Esse parâmetro significa a vulnerabilidade ou suceptibilidade à erosão do solo, que é a recíproca da sua resistência à erosão. A erodibilidade é a única variável, na EUPS, relacionada com as características do solo, estando relacionada com as interações físico-químicas, biológicas e mineralógicas do solo (Ahmed, 2009). O fator $\mathrm{K}$ (erodibilidade do solo) foi determinado inicialmente, a partir da edição de feições (arquivos vetoriais) referentes aos tipos de solos da BHRSC mapeados no ano de 2016, a princípio, para o Estado do Espírito Santo. $\mathrm{O}$ referido arquivo foi fornecido pelo GEOBASES (Geobases, 2020). Posteriormente, o fator K foi determinado pela consulta dos dados numéricos inerentes à cada tipo de solo segundo Corrêa, Moraes e Pinto (2015) e Demarchi e Zimback (2014).

A inserção de todas as equações foi feita na ferramenta "raster calculator", também conhecida como álgebra de mapas, que permite trabalhar com mapas a partir das equações consideradas neste trabalho e inseridas no programa ArcGIS®. Após a obtenção de todos os componentes da equação, a erosão potencial foi classificada conforme o método adotado por Durães e Mello (2016). Foram obtidos, ainda, dados estatísticos para os fatores L, S, LS (fator topográfico) e para a erosão potencial.

\section{RESULTADOS E DISCUSSÃO}

A erosividade (fator R) estimada foi igual a 6.797,20 MJ ha $\mathrm{mm}^{-1}$, o que pode ser classificada como "moderada a alta", conforme a classificação abordada por Carvalho (2008). Nas pastagens da BHRSC, foram identificados dois tipos de solos predominantes, que são: cambissolo háplico e nitossolo vermelho. Ambos possuem valores de erodibilidade (fator K) iguais a, respectivamente, 0,036 (Corrêa, Moraes \& Pinto, 2015) e 0,039 (Demarchi \& Zimback, 2014). O cambissolo háplico abrange 77,775\% das pastagens estudadas, ao passo que o nitossolo vermelho possui 22,225\% de ocupação. 
O fator comprimento de rampa (L) nas pastagens da BHRSC compreende valores que vão de 5 a 12,164, com média aritmética de 5,434 e desvio padrão igual a 0,366. Por sua vez, o fator declividade (S) varia de 0 a 221,783, com média aritmética de 38,997 e desvio padrão igual a 19,412. Os fatores L e S (fator topográfico), juntos, apresentam números que vão de 0 a 27,848, com média aritmética de 2,244 e desvio padrão igual a 1,391.

As áreas de pastagem da BHRSC possuem valores de erosão potencial que variam de 0 ton/ha.ano a 6814 ton/ha.ano, com média aritmética de 569,740 ton/ha.ano e desvio padrão igual a 345,013 ton/ha.ano. A classe de intensidade com maior presença é a "moderada a forte". Todavia, quando somadas, as classes "moderada a forte" e "forte" correspondem a 65,666\%. Já as classes de menor intensidade, a "fraca" e "moderada", juntas, representam apenas 33,652\%. A Tabela 1 e a Figura 5 apresentam, respectivamente, os dados de área (em \%) para cada classe de intensidade à erosão e o mapa de perda natural de solos das áreas de pastagem da BHRSC.

Tabela 1 - Área para cada classe de intensidade à erosão

\begin{tabular}{|c|c|c|}
\hline Classes (ton/ha.ano) & Área (\%) & Área acumulada (\%) \\
\hline Fraca (<400) & 13,957 & 13,957 \\
\hline Moderada (400 - 800) & 19,695 & 33,652 \\
\hline $\begin{array}{c}\text { Moderada a forte }(800- \\
\text { 1600) }\end{array}$ & 42,819 & 76,471 \\
\hline Forte $(1600-2400)$ & 22,847 & 99,318 \\
\hline Muito forte $(>2400)$ & 0,682 & 100,000 \\
\hline
\end{tabular}

Fonte: Elaborado pelo Autor (2020)

Figura 5 - Mapa de erosão potencial das pastagens da BHRSC

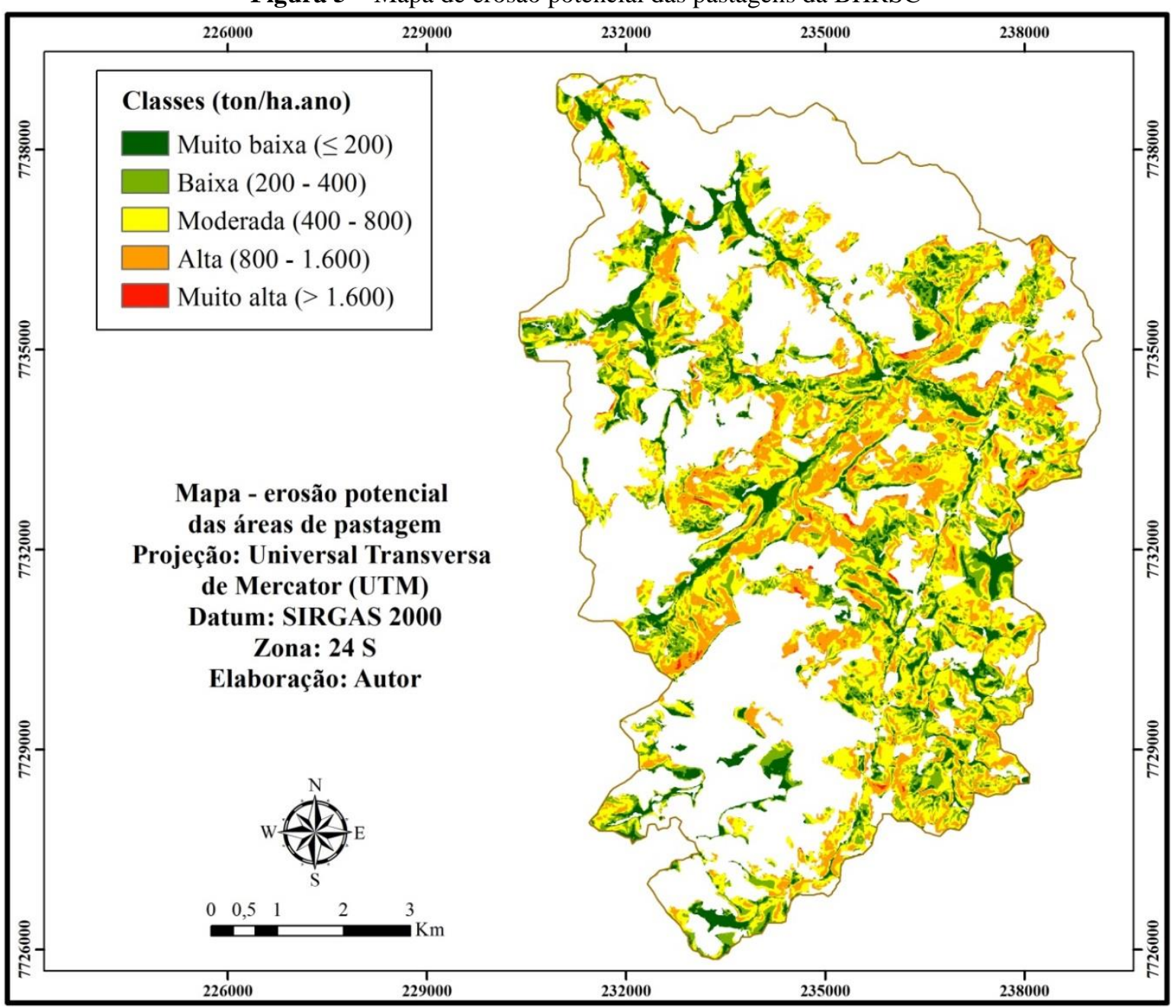

Fonte: Elaborado pelo Autor (2020). 
Os valores de potencial natural de erosão obtidos indicam que as pastagens da BHRSC possuem intensidades compreendidas de média a forte à erosão. Tal constatação pode ser atribuída ao desconhecimento por parte dos produtores rurais acerca dos locais mais propícios à instalação das pastagens. No que se refere à EUPS, os valores podem ser justificados, principalmente, pelas irregularidades do relevo local. O comprimento de rampa e a declividade, representados pelos fatores $\mathrm{L}$ e $\mathrm{S}$, respectivamente, influenciam na velocidade de escoamento superficial, favorecendo a erosão em termos de tamanho e quantidade de material transportado (Silva et al, 2015). Já os índices de erodibilidade dos solos têm fraca contribuição no processo de perdas do solo, agindo como amenizador na equação de perdas do solo (Cumbane, Madeira \& Abrantes, 2015). Portanto, uma parte das pastagens da BHRSC ocupa áreas com maiores irregularidades do relevo, em termos de comprimento de rampa e declividade. Nesses locais, deve-se haver grande atenção quanto à perda de solos, que pode ser influenciada conforme o tipo de manejo empregado.

No município de Muniz Freire, que abrange as pastagens da BHRSC, o nível de degradação dos solos nas pastagens vem se acentuando devido à falta de medidas conservacionistas no avanço de áreas com pastagens extensivas e construção e manutenção de estradas e carreadores com tecnologia inadequada. Um exemplo de manejo incorreto é a mecanização "morro abaixo" do arado empregado em algumas terras destinadas à pecuária. Um dos principais problemas da atividade é a presença de pastagens malformadas, manejadas inadequadamente e, portanto, degradadas, de acordo com o Instituto Capixaba de Pesquisa, Assistência Técnica e Extensão Rural (Incaper, 2010). Na pecuária intensiva, com o uso e o manejo muitas vezes inadequados do solo, ocorre a alteração da cobertura vegetal de grandes áreas e, disso, decorre o processo de degradação do solo e dos recursos hídricos. Essa deterioração tem como consequência uma série de mudanças físicas, químicas, biológicas e hidrológicas, provocando a diminuição da capacidade produtiva do solo (Panachuki, 2003). Nesse sentido, o manejo incorreto da pastagem associada à expressiva tendência natural à erosão pode acarretar prejuízos graves em termos ambientais e de produtividade agrícola na BHRSC. Além do mais, os resultados evidenciam um planejamento incorreto da ocupação da pecuária, pois várias pastagens ocupam áreas naturalmente propícias à erosão.

As diferentes práticas conservacionistas empregadas nas pastagens, em nível de bacia hidrográfica, devem ser tratadas da maneira mais racional possível, para assim conservar os recursos naturais no âmbito das bacias hidrográficas e contribuir diretamente na garantia da qualidade de suas águas (Braz et al., 2017). É imprescindível, então, uma melhor organização do manejo da pecuária para que seja feito o controle da movimentação do gado, além do aprimoramento de técnicas de sistemas criação. Outra medida a ser tomada para reduzir o sobre pastoreio é a criação de sistemas silvipastoris que melhoram a gestão dos sistemas de pastejo como a integração lavoura-pecuária. Ressaltam-se como benefícios ambientais dessa técnica a conservação e renovação dos recursos naturais por manterem árvores no ambiente de pastejo, pois as plantas de grande porte utilizadas (madeireiras, frutíferas, ou forrageiras) servem de alimento para os animais. Portanto, deve-se descentralizar a produção industrial de animais para áreas de cultivo mais acessíveis, onde os resíduos podem ser reciclados, sem contaminar os solos e a água doce (Wust, Tagliani \& Concato, 2015). Tais sugestões são indispensáveis para as pastagens da BHRSC, sendo capazes, por exemplo, de auxiliar na correta gestão dos recursos hídricos ali existentes. Outra medida relevante é o fornecimento aos pecuaristas locais de informações de medidas conservacionistas voltadas à conservação dos solos, principalmente nas áreas com maior tendência natural à erosão.

\section{CONCLUSÕES}

A maior parte das pastagens da BHRSC possui intensidades naturais à erosão caracterizadas como média. Todavia, em uma parcela da área estudada, há forte tendência natural à erosão, o que pode ser agravada com o manejo incorreto da pecuária. A ocupação da pastagem na BHRSC, portanto, ocupa parcialmente locais que apresentam alta potencialidade à erosão, o que também denota um mau planejamento da ocupação da pecuária em alguns locais da referida sub-bacia.

A partir dos resultados obtidos e das informações discutidas, pode-se dizer que os objetivos pretendidos foram atendidos. Todavia, este trabalho evidencia outras vertentes a serem estudadas. Como não envolveu trabalhos práticos, é de extrema importância que, para a continuidade desse estudo, sejam pesquisadas técnicas de 
manejo empregadas na pecuária da BHRSC, bem como pesquisas que envolvam os impactos da pecuária na dinâmica dos recursos hídricos ali existentes.

\section{AGRADECIMENTOS}

À Fundação de Amparo à Pesquisa do Estado do Espírito Santo pelo subsídio financeiro fornecido para a realização das pesquisas.

\section{REFERENCIAS}

ANA - AGÊNCIA NACIONAL DE ÁGUAS. (2020). Encontre mapas interativos, conjuntos de dados geográficos, imagens de satélite e outros serviços. Recuperado em 29 de junho de 2020, de http://metadados.ana.gov.br/geonetwork/srv/pt/main.home.

AHMED, C. R. M. (2009). Fatores que influenciam a erodibilidade nos solos do município de Campos dos Goytacazes-RJ sob uma análise multicritério. Dissertação de Mestrado, Universidade Estadual do Norte Fluminense Darcy Ribeiro, Campos dos Goytacazes. Recuperado em 20 de agosto de 2020, de http://uenf.br/posgraduacao/engenharia-civil/wp-content/uploads/sites/3/2015/09/CLARISSA-REGINAMASIERO-AHMED1.pdf

BERTONI, J., \& LOMBARDI NETO, F. (1990). Conservação do solo. (3a ed.) São Paulo: Ícone Editora.

BERTONI, J., \& LOMBARDI NETO, F. (1999). Conservação do solo. (4a ed.) São Paulo: Icone Editora.

BRAZ, A. M., BRAZ, A. M., BONI, P. V., GARCIA, P. H. M., PINTO, A. L., \& OLIVEIRA, I. J. DE. (2017). Uso, cobertura e manejo da terra: contribuições teórico-metodológicas e subsídios à conservação ambiental na bacia hidrográfica do córrego Ribeirãozinho, Selvíria/MS. Caminhos de Geografia, Uberlândia, 18 (64), $310-327$. $\begin{array}{lllllll}\text { Recuperado em } & 18 & \text { de } & \text { agosto } & \text { de } & 2020, & \text { de }\end{array}$ http://www.seer.ufu.br/index.php/caminhosdegeografia/article/view/40936/21671

BUENO, C. R. P., ARRAES, C. L., \& MIQUELONI, D. P. (2011). Aplicação do sistema de informação geográfica para determinação do fator topográfico em bacias hidrográficas. Revista Brasileira de Tecnologia Aplicada nas Ciências Agrárias, Guarapuava, 4 (2), 30-47.

CARVALHO, N. O. (2008). Hidrossedimentologia prática. (2a ed.) Rio de Janeiro: Interciência.

CARVALHO, A. T. F. (2020). Bacia hidrográfica como unidade de planejamento: discussão sobre os impactos da produção social na gestão de recursos hídricos no Brasil. Caderno Prudentino de Geografia, Presidente Prudente, 1 (42), 140-161. Recuperado em 20 de agosto de 2020, de https://revista.fct.unesp.br/index.php/cpg/article/view/6953

CORRÊA, E. A., MORAES, I. C., \& PINTO, S. DOS A. F. (2015). Estimativa da erodibilidade e tolerância de perdas de solo na região do centro leste paulista. Geociências, 34 (4), 848-860. Recuperado em 15 de agosto de 2020, de http://www.ppegeo.igc.usp.br/index.php/GEOSP/article/view/9035

CORRÊA, E. A., \& PINTO, S. A. F. S. (2012). Avaliação do potencial natural de erosão da bacia hidrográfica do córrego Monjolo Grande (Ipeúna-SP). Geonorte, 2 (4), 1356-1367. Recuperado em 19 de agosto de 2020, de https://periodicos.ufam.edu.br/index.php/revista-geonorte/article/view/2194/2065 
CUIABANO, M. DO N., NEVES, S. M. A. DA S., NEVES, M. C. M., SERAFIM, M. E., \& NEVES, R. J. (2017). Vulnerabilidade ambiental à erosão hídrica na sub-bacia do córrego do Guanabara/ Reserva do CabaçalMT Brasil. Geociências, São Paulo, 36 (1), 138-153. Recuperado em 16 de agosto de 2020, de https://www.revistageociencias.com.br/geociencias-arquivos/36/volume36_1_files/36-1-artigo-09.pdf

CUMBANE, B. L., MADEIRA, M. A. V., \& ABRANTES, M. DA G. (2015). Aplicação de Sistemas de Informação Geográfica para a determinação do Potencial Natural de Erosão dos solos no Distrito de Sussundenga - Moçambique. Anais do Congresso Brasileiro de Ciência do Solo, Natal, RN, Brasil, 35. Recuperado em 16 de agosto de 2020, de https://eventosolos.org.br/cbcs2015/arearestrita/arquivos/398.pdf

DEMARCHI, J. C., \& ZIMBACK, C. R. L. (2014). Mapeamento, erodibilidade e tolerância de perda de solo na sub-bacia do ribeirão das Perobas. Energia na Agricultura, Botucatu, 29 (2), 102-114. https://doi.org/10.17224/EnergAgric.2014v29n2p102-114

DE ZEN, S., BARIONI, L. G., BONATO, D. B. B., ALMEIDA, M. H. S. P. DE., \& RITTL, T. F. (2008). Pecuária de corte brasileira: impactos ambientais e emissões de gases efeito estufa (GEE). 2008. Recuperado em 19 de outubro de 2020, de https://www.cepea.esalq.usp.br/br/documentos/texto/pecuaria-de-corte-brasileiraimpactos-ambientais-e-emissoes-de-gases-efeito-estufa-gee.aspx

DURÃES, M. F., \& MELLO, C. R. (2016). Distribuição espacial da erosão potencial e atual do solo na Bacia Hidrográfica do Rio Sapucaí, MG. Engenharia Sanitária e Ambiental, 21 (4), 677-685. https://doi.org/10.1590/s1413-41522016121182

EMBRAPA. (2020). Clima. Recuperado em 2 de outubro de 2020, de https://www.cnpf.embrapa.br/pesquisa/efb/clima.htm

GALDINO, S. (2012). Estimativa da perda de terra sob pastagens cultivadas em solos arenosos da bacia hidrográfica do Alto Taquari - MS/MT. Tese de Doutorado, Faculdade de Engenharia Agrícola, Universidade Estadual de Campinas, Campinas, SP, Brasil. Recuperado em 5 de outubro de 2020, de https://www.embrapa.br/busca-de-publicacoes/-/publicacao/937957/estimativa-da-perda-de-terra-sob-pastagenscultivadas-em-solos-arenosos-da-bacia-hidrografica-do-alto-taquari---msmt

GEOBASES. (2020). IEMA - mapeamento ES - 2012-2015. Recuperado em 1 de junho de 2020, de https://geobases.es.gov.br/links-para-mapes1215

GOMES, C. S. (2019). Impactos da expansão do agronegócio brasileiro na conservação dos recursos naturais. Cadernos do Leste, Belo Horizonte, 19 (19), 63-78. Recuperado em 10 de agosto de 2020, de https://periodicos.ufmg.br/index.php/caderleste/article/view/13160

INSTITUTO JONES DOS SANTOS NEVES. (2020). Shapefiles. Recuperado em 3 de julho de 2020, de http://www.ijsn.es.gov.br/mapas/

INCAPER. (2010). Programa de assistência técnica e extensão rural PROATER 2011 - 2013: Muniz Freire. Recuperado em 1 de julho de 2020, de https://incaper.es.gov.br/media/incaper/proater/um nicipios/Caparao/Muniz_Freire.pdf

LANZA, D. S. (2011). Diagnóstico da erosão laminar na alta e média bacia do Rio Paraopeba. Dissertação de Mestrado, Departamento de Geografia, Universidade Federal de Minas Gerais, Belo Horizonte, MG, Brasil. Recuperado em 14 de agosto de 2020, de https://repositorio.ufmg.br/handle/1843/MPBB-8MAPD4 
LIMA, G. A. DE., GENEROSO, C. M., SANTOS, C. M. DOS., SILVA, L. A., \& SOUSA, R. G. DE. (2016). Bacia hidrográfica como unidade de planejamento e gestão: estudo de caso ribeirão Isidoro. Anais do Congresso Brasileiro de Gestão Ambiental, Campina Grande, PB, Brasil, 7. Recuperado em 20 de agosto de 2020, de http://www.ibeas.org.br/congresso/Trabalhos2016/VIII-074.pdf

LOMBARDI NETO, F., \& MOLDENHAUER, W. C. (1992). Erosividade da chuva: sua distribuição e relação com as perdas de solo em Campinas (SP). Bragantia, 51 (2), 189-196. https://doi.org/10.1590/S000687051992000200009

MAGAlHÃES FILHO, F. J. C., AYRES, F. M., \& SOBRINHO, T. A. (2014). Integrando SIG e USLE para mapeamento da perda de solo em área de proteção ambiental. Agrarian, Dourados, 7 (26), 552-559. Recuperado em 16 de agosto de 2020, de https://ojs.ufgd.edu.br/index.php/agrarian/article/view/2760/1983

MORAIS, R. C. DE S., \& SALES, M. C. L. Estimativa do potencial natural de erosão dos solos na bacia hidrográfica do Alto Gurguéia, Piauí-Brasil, com uso de Sistema de Informação Geográfica. Caderno de Geografia, Belo Horizonte, v. 27, n. 1, p. 84-105, 2017. https://doi.org/10.5752/p.2318-2962.2017v27nesp1p84

MOURA, M. M., FONTES, C. DOS S., SANTOS, M. H. DOS., ARAUJO FILHO, R. N., HOLANDA, F. S. R. (2017). Estimativa de perda de solo no baixo São Francisco sergipano. Scientia Agraria, 18 (2), 126-135. http://dx.doi.org/10.5380/rsa.v18i2.50143

OLIVEIRA, F. F., SANTOS, R. E. S., \& ARAUJO, R. DA C. DE. (2018). Processos erosivos: dinâmica, agentes causadores e fatores condicionantes. Revista Brasileira de Iniciação Científica, Itapetininga, 5 (3), 60-83. Recuperado em 7 de agosto de 2020, de https://periodicos.itp.ifsp.edu.br/index.php/IC/article/view/699/928

PANACHUKI, E. (2003). Infiltração de água no solo e erosão hídrica, sob chuva simulada, em Sistema de integração Lavoura-Pecuária. Dissertação de Mestrado, Programa de Pós-Graduação em Agronomia, Universidade Federal de Mato Grosso do Sul, Dourados, MS, Brasil. Recuperado em 22 de agosto de 2020, de http://www.ufrrj.br/institutos/it/deng/daniel/Downloads/Material/Teses\%20Orientadas/Tese\%20Infiltracao\%20de $\% 20$ agua\%20no\%20solo.pdf

PRESTES, V., \& CORRÊA, E. A. (2019). Potencial Natural de Erosão no alto curso da bacia hidrográfica do Arroio Quilombo, RS. Anais do Simpósio Brasileiro de Geografia Física Aplicada, Fortaleza, CE, Brasil, 18. Recuperado em 10 de agosto de 2020, de http://www.editora.ufc.br/images/imagens/pdf/geografia-fisica-e-asmudancas-globais/620.pdf

SANTOS, A. R. DOS., LOUZADA, F. L. R. DE O., EUGÊNIO, F. C. (2010). ARCGIS 9.3 total: aplicações para dados espaciais. Alegre: CAUFES. Recuperado em 1 de julho de 2020, de http://www.mundogeomatica.com.br/Livros/Livro_ArcGIS\%209.3_Aplicacoes_Para_

Dados_Espaciais/Livro_ArcGIS93_Total.pdf

SILVA, A. M., HUANG, C. H., FRANCESCONI, W., SAINTIL, T., \& VILLEGAS, J. (2015). Using landscape metrics to analyze micro scale soil erosion processes. Ecological Indicators, 56, 184-193. https://doi.org/10.1016/j.ecolind.2015.04.004

TEODORO, V. L. I., TEIXEIRA, D., COSTA, D. J. L., \& FULLER, B. B. (2007). O conceito de bacia hidrográfica e a importância da caracterização morfométrica para o entendimento da dinâmica ambiental local. Revista UNIARA, 11 (1): 136-157. https://doi.org/10.25061/2527-2675/ReBraM/2007.v11i1.236 
WISCHMEIER, W. H., \& SMITH, D. D. (1962). Rainfail erosion. Advances in Agronomy, 14, 109-148. https://doi.org/10.1016/S0065-2113(08)60437-X

WUST, C., TAGLIANI, N., \& CONCATO, A. C. (2015). A pecuária e sua influência impactante ao meio ambiente. Anais do Congresso Brasileiro de Gestão Ambiental, Porto Alegre, RS, Brasil, 6. Recuperado em 22 de agosto de 2020, de https://www.ibeas.org.br/congresso/Trabalhos2015/V-025.pdf 